\title{
Preparation and thermal properties of polyethylene-based carbonized fibers
}

\author{
Kwan-Woo Kim ${ }^{1,2}$, Hye-min Lee', Byoung Suhk Kim², Seon-Hwan Hwang ${ }^{3}$, \\ Lee-Ku Kwac ${ }^{4}$, Kay-Hyeok An ${ }^{1}$ and Byung-Joo Kim ${ }^{1, \star}$ \\ ${ }^{1}$ R\&D Division Korea Institute of Carbon Convergence Technology, Jeonju, Jeollabuk-do 561-844, Republic Korea \\ ${ }^{2}$ Department of Organic Materials \& Fiber Engineering Chonbuk National University, Jeonju, Jeollabuk-do 561-756, Republic Korea \\ ${ }^{3}$ LG chemical, Republic Korea \\ ${ }^{4}$ Department of Carbon Fusion Engineering, Jeonju University, Jeollabuk-do 560-759, Republic Korea
}

\section{Article Info}

Received 12 October 2014 Accepted 7 December 2014

*Corresponding Author E-mail: kimbj2015@gmail.com Tel: $+82-63-219-3720$

\section{Open Access}

DOI: http://dx.doi.org/

10.5714/CL.2015.16.1.062

This is an Open Access article distributed under the terms of the Creative Commons Attribution Non-Commercial License (http://creativecommons.org/licenses/ by-nc/3.0/) which permits unrestricted non-commercial use, distribution, and reproduction in any medium, provided the original work is properly cited.

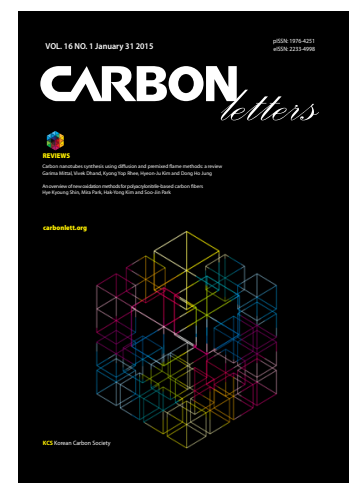

http://carbonlett.org

pISSN: $1976-4251$

elSSN: 2233-4998

Copyright $\odot$ Korean Carbon Society

\section{Abstract}

In this study, carbonized fibers were prepared by using acidically cross-linked LDPE fibers. The surface morphologies of the carbonized fibers were observed by SEM. The effects of cross-linking process temperatures were studied using thermal analyses such as DSC and TGA. The melting and heating enthalpy of the fibers decreased as the cross-linking temperature increased. The cross-linked fibers had a carbonization yield of over $50 \%$. From SEM results the highest yield of carbonized LDPE-based fibers was obtained by cross-linking at a sulfate temperature $\left(170^{\circ} \mathrm{C}\right)$. As a result, carbonation yield of the carbonized fibers was found to depend on the functions of the cross-linking ratio of the LDPE precursors.

Key words: carbon fiber, sulfuric acid, cross-linking, polyolefin, carbon fiber precursor

\section{Introduction}

Carbon fiber is a superb material for applications in the aerospace, automobile, and sporting goods industries, due to its excellent mechanical, thermal, and electrical characteristics. The carbon fiber market is expected to grow $6.3 \%$ year after year until 2016. [1-4].

However, due to the high cost of petroleum-based precursors and their associated processing costs, carbon fiber remains a specialty product and as such has been limited to use in high-end aerospace, sporting goods, automotive, and specialist industrial applications [5-7].

The price of carbon fibers is primarily driven by its manufacture. Within the manufacturing process, petroleum-based precursors account for just over half the cost of the finished carbon fibers, and so across the industry, manufacturing costs are dominated by the high cost of carbon fiber precursor materials [8]. Carbon fibers are usually produced from polyacrylonitrile (PAN), pitch, and rayon materials. Industrial users of carbon fibers generally utilize commercially popular PAN-based carbon fiber [9-11]. However, the high cost of PAN precursors, which make up $43 \%$ of the carbon fiber manufacturing cost, limits its utilization in general performance grade applications. [12-14].

To date, investigations into the manufacture of low-cost carbon fiber have been limited to a small number of organizations owing to the magnitude of the effort required, a limited availability of expertise, and equipment. Approaches involve reducing cost by using lower cost materials, by reducing the cost of processing, or by a combination of the two [15-19].

Polyolefins (PE, PP, etc.) can easily be used to produce fibers at low cost, and have been applied as industrial fiber. Also, polyolefin has a high carbonization ratio in the carbonization process, and it can be melt spun. Because of these advantages, polyolefin 
is promising for the manufacture of a low-cost carbon fiber. Low-density polyethylenes (LDPE) are attractive as carbon precursors due to their high carbon content and ease of manufacture. Also, highly oriented LDPE, with extraordinary physical and mechanical properties, are available today. However, being thermoplastic, they melt at a fairly low temperature, losing their form. These precursors have to be stabilized by introducing cross-links into the polymer structure, so that they can withstand the high carbonization temperatures [20-22].

LDPE are usually cross-linked in four kind different ways: by energy radiation, peroxide, silane coupling agents, and sulfonation cross-linking [23]. Among the four cross-linking methods used, the sulfonation cross-linking method has the advantage of high cross-linking density. With sulfonation crosslinking it is possible to easily adjust the cross-linking density by temperature control. The sulfonating agent in this process is typically sulfuric acid, chlorosulfonic acid, or a combination thereof. The sulfuric acid cross-linking method uses concentrated sulfuric acid ( 90 wt. $\%$ or more). The concentrated sulfuric acid has a strong dehydrating action because it is strongly hygroscopic. In contact with organic material it has the property of absorbing hydrogen and oxygen in the form of water molecules. [24-26].

In the present study, we tried to develop a low price carbon fiber from LDPE-based fibers through sulfonation cross-linking. Various analytical techniques were utilized to investigate the morphology and thermal properties of the precursors and final carbonized fibers. Finally, an exploration of the properties of the carbonized fibers demonstrated the increased carbon yield and clearly fibrous form of the LDPE-based fibers.

\section{Experiment Details}

\subsection{Materials and methods}

Concentrated sulfuric acid (H2SO4, Daejung Chem, Korea) and low-density polyethylene (LDPE, LG Chem, Korea) were obtained for the experiments. The cross-linking of LDPE was

$$
\begin{aligned}
& \mathrm{H}_{2} \mathrm{SO}_{4} \rightleftharpoons \mathrm{H}_{2} \mathrm{O}+\mathrm{SO}_{3}
\end{aligned}
$$

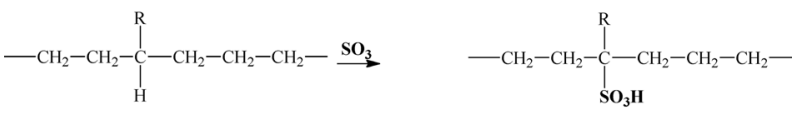

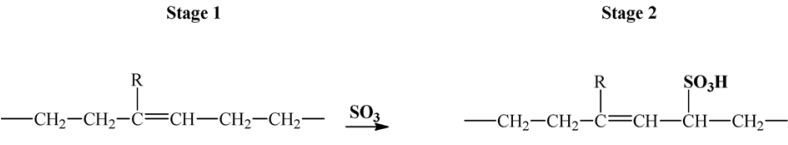

$$
\begin{aligned}
& +\mathrm{SO}_{2}+\mathrm{H}_{2} \mathrm{O} \\
& \begin{array}{ll}
\text { Stage } 3 & \text { Stage } 4
\end{array}
\end{aligned}
$$

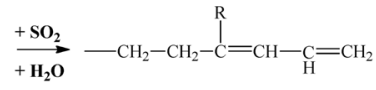

$$
\begin{aligned}
& \text { Stage } 5
\end{aligned}
$$

Fig. 1. Reaction mechanism of sulfuric acid with LDPE introducing sulfuric groups and carbon-to-carbon double bonds carried out in hot sulfuric acid. The concentrated (98\%) sulfuric acid was heated to a temperature of $130-170^{\circ} \mathrm{C}$. After treatments for a predetermined length of time and temperature, the LDPE was taken out, washed thoroughly in distilled water, and then dried in a constant temperature oven at $60^{\circ} \mathrm{C}$ for $24 \mathrm{~h}$. The completely cross-linked fibers were carbonized in a vertical quartz tubular furnace at $900^{\circ} \mathrm{C}$ for $30 \mathrm{~min}$ (nitrogen purging) with the heating rate of $5^{\circ} \mathrm{C} / \mathrm{min}$ at slight weight tension. The reaction mechanism of the sulfuric acid with LDPE is illustrated in Fig.1 [27].

\subsection{Characterization}

The effects of the temperature characteristics of the crosslinking processes were studied using thermal analyses, such as differential scanning calorimetry (DSC-60, SHIMADZU, Japan) and thermogravimetric analysis (TGA-50, SHIMADZU, Japan). DSC analysis of the heating and cooling rate of $10^{\circ} \mathrm{C} /$ min was used with a temperature range from 30 to $300^{\circ} \mathrm{C}$. The sample was purged with nitrogen gas to maintain an insert environment, at a flow rate of $20 \mathrm{ml} / \mathrm{min}$. And, TGA analysis of all samples were examined under a pure nitrogen atmosphere. Each of the samples were heated from $30^{\circ} \mathrm{C}$ up to $900^{\circ} \mathrm{C}$ at a rate of 10 ${ }^{\circ} \mathrm{C} / \mathrm{min}$. The surface morphologies of the carbonized fibers were observed by scanning electron microscope (AIS2000C, Seron Tech, Korea). SEM analysis was performed at high voltage (15 $\mathrm{kV})$ after gold coating.
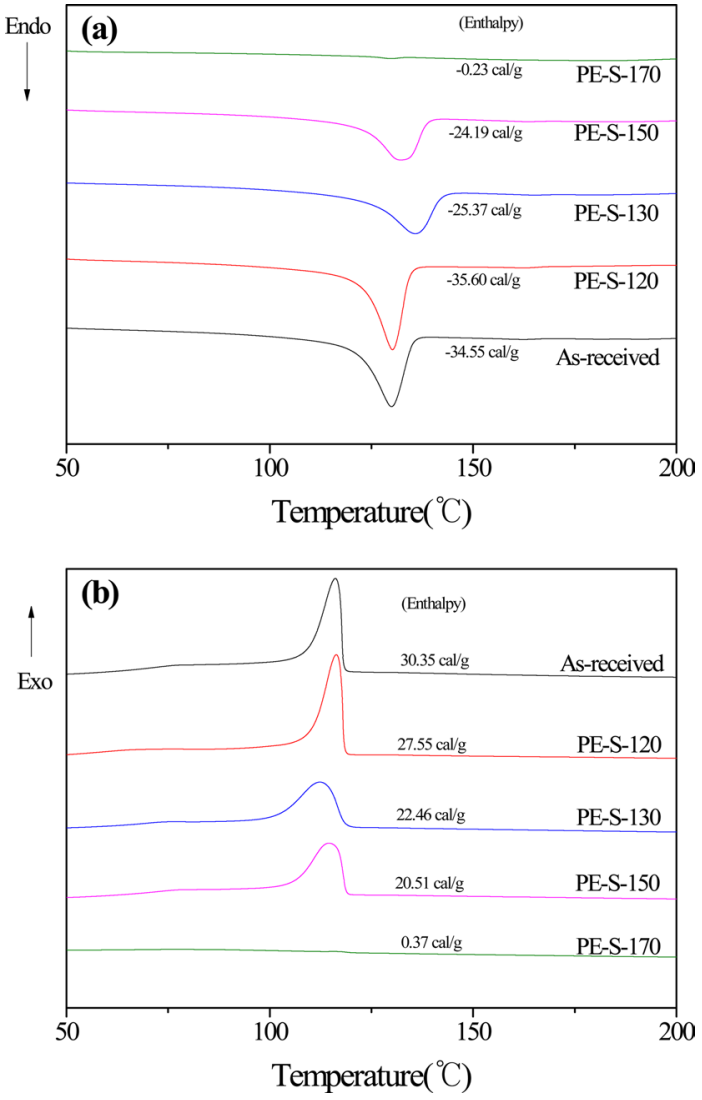

Fig. 2. DSC curves of the cross-linked LDPE fibers treated by sulfuric acid with different temperatures: (a) heating (b) and cooling scan. 


\section{Results and Discussion}

\subsection{Calorimetry}

Fig. 2 shows the DSC curves of the LDPE precursor, and LDPE fiber cross-linked by sulfuric acid at different crosslinking temperatures. It shows almost no cross-linking of the LDPE fibers under $120^{\circ} \mathrm{C}$ reaction temperature. But, the $\mathrm{T}_{\mathrm{m}}$ and $\mathrm{T}_{\mathrm{c}}$ enthalpy of the fibers decreased as the cross-linking temperature increased to at least $130^{\circ} \mathrm{C}$. The $\mathrm{T}_{\mathrm{m}}$ enthalpy of the fibers decreased as the cross-linking temperature increased. That is due to the decomposition and change of crystal structures from extended to folded morphology. The $T_{m}$ and $T_{c}$ temperature of the extended-chain polyethylene was higher than that of foldedchain polyethylene. The endotherm points and exotherm points disappeared after sufficient sulfonation due to the penetration and diffusion of sulfuric acid molecules from the surface of the crystals to their center. The DSC peak of sufficiently crosslinked LDPE disappeared by increased cross-linked density at $170^{\circ} \mathrm{C}$.

\subsection{Thermogravimetric analysis}

Fig. 3 shows the increasing weight retention with increasing cross-linked temperature. And, Table 1 lists the TGA results for LDPE fiber cross-linked by sulfuric acid with different temperatures. Decomposition temperatures for the all LDPE fibers were

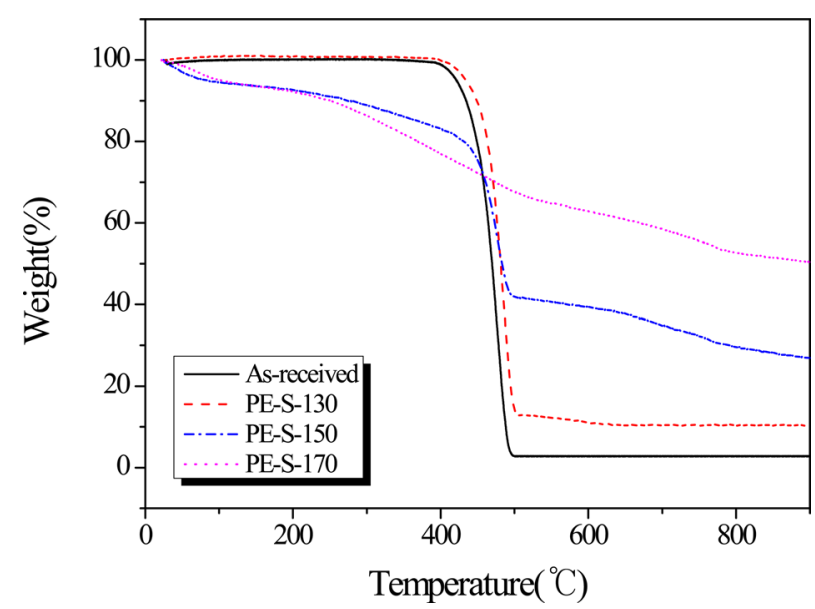

Fig. 3. TGA curves of the cross-linked LDPE fibers treated by sulfuric acid with different temperatures. about $500^{\circ} \mathrm{C}$ except PE-S-170. The thermal stability, based on the polymer decomposition temperature (PDT) and integral procedural decomposition temperature (IPDT), rose with increasing sulfonation temperature. As the crosslinking temperature

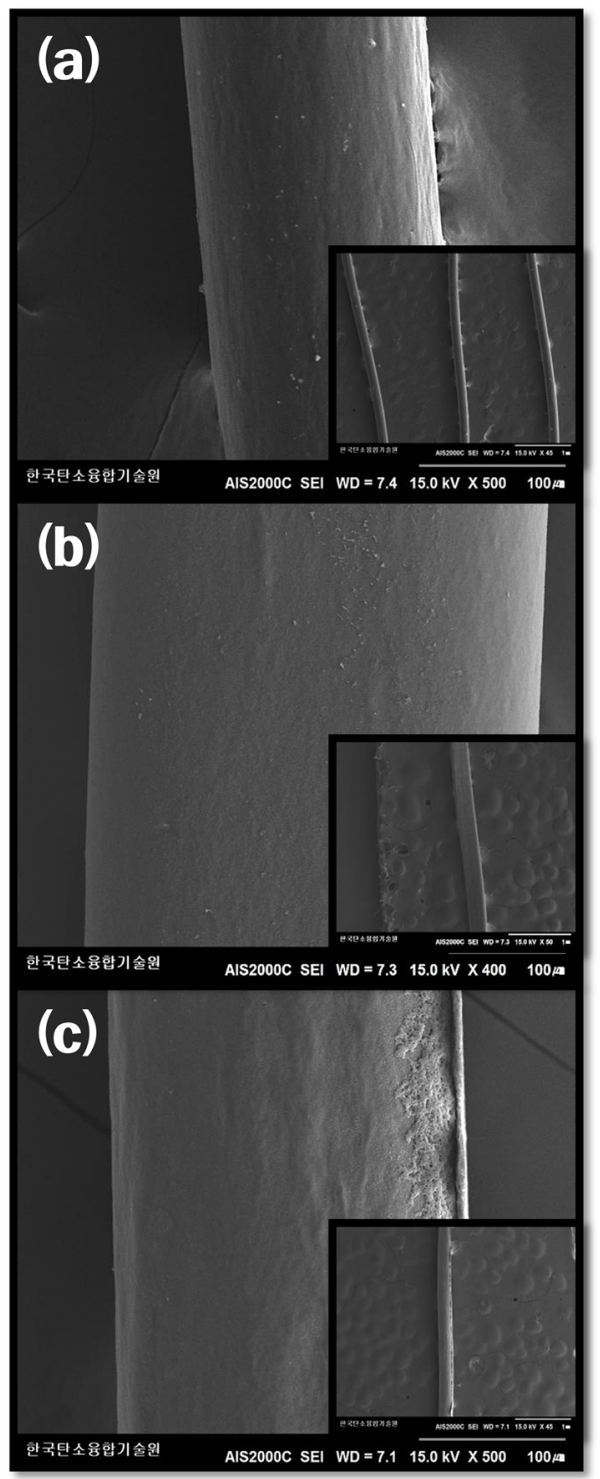

Fig. 4. SEM image of the cross-linked LDPE fibers treated by sulfuric acid: (a) As-received, (b) cross-linked LDPE fibers, (c) carbonized LDPE fiber.

Table 1. TGA Curve Parameters of the Cross-Linked LDPE treated by Sulfuric Acid with Different Temperatures.

\begin{tabular}{|c|c|c|c|c|c|c|}
\hline TGA & $\operatorname{PDT}\left({ }^{\circ} \mathrm{C}\right)$ & $\mathrm{T}_{\max }\left({ }^{\circ} \mathrm{C}\right)$ & $\mathrm{A}^{*} \mathrm{~K}^{*}$ & IPDT $\left({ }^{\circ} \mathrm{C}\right)$ & Carbon yield $^{\mathrm{a}}(\%)$ & Fibrous form $^{b}$ \\
\hline As-received & 447.32 & 472.80 & 0.541 & 501.18 & 2.78 & $\mathrm{x}$ \\
\hline PE-S-130 & 462.29 & 483.26 & 0.70 & 637.67 & 10.44 & $\mathrm{x}$ \\
\hline PE-S-150 & 454.33 & 477.58 & 1.10 & 985.66 & 26.82 & $\triangle$ \\
\hline PE-S-170 & 238.43 & 492.32 & 2.30 & 2029.73 & 50.27 & 0 \\
\hline
\end{tabular}

$a:$ In the carbonization furnace

$\mathrm{b}: \mathrm{x}$-failed to form, $\triangle$-surface-fractured fiber, $\bigcirc$ - stable fiber 
was increased, the carbonization yield was increased. The crosslinking reaction strengthened decomposition stability and heat exhaustion, resulting from the most densely cross-linked structure at $170^{\circ} \mathrm{C}$. This also enhanced gel-structures in the LDPE, resulting in high carbonization yields. From Table 1, PE-S-170 showed the best weight retention (50.27\%), among all the crossliked samples.

\subsection{Surface morphology analysis}

The surface morphologies of all the LDPE fibers were observed by scanning electron microscope (SEM). SEM images of the LDPE fibers are shown in Fig. 4 (a). As seen in Figure 4 , the morphology of the fibrous surfaces of all specimens was similar to each other. On closer scrutiny of this figure, it can also be found that the fibrous surface morphology differs in roughness. The fibrous form of the samples can be clearly observed as carbonized fibers from Fig. 4 (c). From SEM and TGA results, it can be assumed that proper carbon yield (over 50\%) can lead to good fiber shape after the carbonization.

\section{Conclusion}

In this work, LDPE was used as a precursor and crosslinked by sulfuric acid to obtain a high degree of carbonization. Cross-linking behaviors of the samples were clearly observed with increasing reaction temperatures in sulfuric acid from DSC results. From the TGA results, the residues of the samples increased gradually up to $150^{\circ} \mathrm{C}$ of reaction temperature, then were dramatically enhanced at $170^{\circ} \mathrm{C}$. This result indicates that the cross-linking reaction of the LDPE in sulfuric acid can occur at low temperature, but high temperature (over $\left.170^{\circ} \mathrm{C}\right)$ can radically accelerate the cross-linking reaction. The final residue of 'PE-S-170' was over $50 \%$. In addition, the fibrous states of the samples were clearly observed to be carbonized fibers from the SEM results. From the results, LDPE can be a potentially advantageous material as a carbon fiber precursor.

\section{Acknowledgments}

This study was supported by the "Carbon Valley R\&D Project (Project no.R0003404 and no.A007700147)" funded by the Ministry of Trade, Industry \& Energy (MOTIE), Republic of Korea.

\section{References}

[1] Fitzer E. Pan-based carbon fibers: present state and trend of the technology from the viewpoint of possibilities and limits to influence and to control the fiber properties by the process parameters. Carbon, 27, 621 (1989). http://dx.doi.org/10.1016/00086223(89)90197-8

[2] Park SJ, Kim BJ. Carbon fibers and their composites. In: Park SJ, ed. Carbon Fibers. Springer Series in Materials Science Vol. 210 , Springer, Netherlands, 275 (2015). http://dx.doi.org/10.1007/978-
94-017-9478-7_8.

[3] Kim SY, Kim SY, Lee S, Jo S, Im YH, Lee HS. Microwave plasma carbonization for the fabrication of polyacrylonitrile-based carbon fiber. Polymer, 56, 590 (2015). http://dx.doi.org/10.1016/j.polymer.2014.11.034.

[4] Rahaman MSA, Ismail AF, Mustafa A. A review of heat treatment on polyacrylonitrile fiber. Polym Degrad Stab, 92, 1421 (2007) http://dx.doi.org/10.1016/j.polymdegradstab.2007.03.023.

[5] Edie DD. The effect of processing on the structure and properties of carbon fibers. Carbon, 36, 345 (1998). http://dx.doi.org/10.1016/ S0008-6223(97)00185-1.

[6] Deng W, Lobovsky A, Iacono ST, Wu T, Tomar N, Budy SM, Long T, Hoffman WP, Smith Jr DW. Poly (acrylonitrile-co-1-vinylimidazole): a new melt processable carbon fiber precursor. Polymer, 52, 622 (2011). http://dx.doi.org/10.1016/j.polymer.2010.11.054.

[7] Kim KS, Shim YS, Kim BJ, Meng LY, Lee SY, Park SJ. Present status and applications of carbon fibers-reinforced composites for aircrafts. Carbon Lett, 11, 235 (2010). http://dx.doi.org/10.5714/ CL.2010.11.3.235.

[8] Baker DA, Gallego NC, Baker FS. On the characterization and spinning of an organic-purified lignin toward the manufacture of low-cost carbon fiber. J Appl Polym Sci, 124, 227 (2012). http:// dx.doi.org/10.1002/app.33596.

[9] Yusof N, Ismail AF. Post spinning and pyrolysis processes of polyacrylonitrile (PAN)-based carbon fiber and activated carbon fiber: a review. J Anal Appl Pyrolysis, 93, 1 (2012). http://dx.doi. org/10.1016/j.jaap.2011.10.001.

[10] Huang X. Fabrication and properties of carbon fibers. Materials, 2, 2369 (2009). http://dx.doi.org/10.3390/ma2042369.

[11] Sutasinpromprae J, Jitjaicham S, Nithitanakul M, Meechaisue C, Supaphol P. Preparation and characterization of ultrafine electrospun polyacrylonitrile fibers and their subsequent pyrolysis to carbon fibers. Polym Int, 55, 825 (2006). http://dx.doi.org/10.1002/ pi.2040.

[12] Jie L, Wangxi Z. Structural changes during the thermal stabilization of modified and original polyacrylonitrile precursors. J Appl Polym Sci, 97, 2047 (2005). http://dx.doi.org/10.1002/app.21916.

[13] Kadla JF, Kubo S, Venditti RA, Gilbert RD, Compere AL, Griffith W. Lignin-based carbon fibers for composite fiber applications. Carbon, 40, 2913 (2002). http://dx.doi.org/10.1016/S00086223(02)00248-8.

[14] Zhang WX, Wang YZ. Manufacture of carbon fibers from polyacrylonitrile precursors treated with $\mathrm{CoSO}_{4}$. J Appl Polym Sci, 85, 153 (2002). http://dx.doi.org/10.1002/app.10560.

[15] Maradur SP, Kim CH, Kim SY, Kim B-H, Kim WC, Yang KS Preparation of carbon fibers from a lignin copolymer with polyacrylonitrile. Synth Met, 162, 453 (2012). http://dx.doi.org/10.1016/j. synthmet.2012.01.017.

[16] Shen Q, Zhang T, Zhang WX, Chen S, Mezgebe M. Lignin-based activated carbon fibers and controllable pore size and properties. J Appl Polym Sci, 121, 989 (2011). http://dx.doi.org/10.1002/ app.33701.

[17] Ibrahim MNM, Ahmed-Haras MR, Sipaut CS, Aboul-Enein HY, Mohamed AA. Preparation and characterization of a newly water soluble lignin graft copolymer from oil palm lignocellulosic waste. Carbohydr Polym, 80, 1102 (2010). http://dx.doi.org/10.1016/j. carbpol.2010.01.030.

[18] Baker DA, Rials TG. Recent advances in low-cost carbon fiber manufacture from lignin. J Appl Polym Sci, 130, 713 (2013). http:// 
dx.doi.org/10.1002/app.39273.

[19] Math F, Marianneau G. A new method for manufacturing carbonfibre microelectrodes. J Neurosci Methods, 52, 149 (1994). http:// dx.doi.org/10.1016/0165-0270(94)90123-6.

[20] Hyslop DK, Parent JS. Dynamics and yields of AOTEMPO-mediated polyolefin cross-linking. Polymer, 54, 84 (2013). http://dx.doi. org/10.1016/j.polymer.2012.11.013.

[21] Camara S, Gilbert BC, Meier RJ, van Duin M, Whitwood AC. EPR studies of peroxide decomposition, radical formation and reactions relevant to cross-linking and grafting in polyolefins. Polymer, 47, 4683 (2006). http://dx.doi.org/10.1016/j.polymer.2006.04.015.

[22] Zheng Y, Pan L, Li YG, Li YS. Synthesis and characterisation of novel functional polyolefin containing sulfonic acid groups Eur Polym J, 44, 475 (2008). http://dx.doi.org/10.1016/j.eurpolymj.2007.11.017.

[23] Sirisinha K, Boonkongkaew M, Kositchaiyong S. The effect of silane carriers on silane grafting of high-density polyethylene and properties of crosslinked products. Polym Test, 29, 958 (2010). http://dx.doi.org/10.1016/j.polymertesting.2010.08.004.

[24] Postema AR, De Groot H, Pennings AJ. Amorphous carbon fibres from linear low density polyethylene. J Mater Sci, 25, 4216 (1990). http://dx.doi.org/10.1007/BF00581075.

[25] Zhang D, Sun Q. Structure and properties development during the conversion of polyethylene precursors to carbon fibers. J Appl Polym Sci, 62, 367 (1996). http://dx.doi.org/10.1002/(SICI)1097. 4628(19961010)62:2<367::AID-APP11>3.0.CO;2-Z.

[26] Penning JP, Lagcher R, Pennings AJ. The effect of diameter on the mechanical properties of amorphous carbon fibres from linear low density polyethylene. Polym Bull, 25, 405 (1991). http://dx.doi. org/10.1007/BF00316913.

[27] Ihata J. Formation and reaction of polyenesulfonic acid. I. Reaction of polyethylene films with $\mathrm{SO}_{3}$. J Polym Sci A, 26, 167 (1988). http://dx.doi.org/10.1002/pola.1988.080260116. 